\title{
Pembuatan Model Laser Nd-YAG Gelombang Kontinyu Daya Rendah
}

\author{
Muchiar* \\ Pusat Penelitian Fisika - Lembaga Ilmu Pengetahuan Indonesia \\ Kawasan Puspiptek, Serpong, Tangerang, Banten
}

Intisari

Telah dibuat sebuah model laser Nd-YAG gelombang kontinyu daya rendah. Laser dioda $(\lambda=805 \mathrm{~nm})$ digunakan sebagai sumber energi pemompanya. Medium aktifnya adalah kristal Nd-YAG, diameter $3 \mathrm{~mm}$ dan panjang $5 \mathrm{~mm}$. Sistem laser ini juga meliputi sistem pengkolimasian dan pemfokusan berkas laser dioda. Gelombang emisi kristal Nd-YAG yang dipancarkan diukur dengan Optical Spectrum Analyzer. hasilnya menunjukkan terdapat 10 puncak emisi diantara rentang 1040 hingga $1140 \mathrm{~nm}$, sesuai dengan prediksi teoritis. Pengaturan cermin resonator dengan tepat telah menghasilkan berkas laser dengan panjang gelombang 1064 nm, sesuai dengan harapan.

KATA KUNCI: laser Nd-YAG, gelombang kontinyu, laser dioda, resonator plano konkaf.

\section{PENDAHULUAN}

Laser Nd-YAG merupakan salah satu jenis laser zat padat yang disukai, sangat populer dan digunakan secara luas dalam berbagai bidang. Laser yang menggunakan kristal Nd-YAG sebagai medium lasing-nya ini, memiliki koherensi yang baik dan spektrum berkas luaran yang sempit, serta dapat diproduksi dengan daya yang sangat bervariasi, mulai dari beberapa milliwatt hingga beberapa kilowatt.

Semua laser zat padat dipompa secara optik, yang berarti eksitasi dari medium aktif dicapai dengan penyerapan cahaya. Pada penelitian ini sebagai sumber energi pemompa telah digunakan laser dioda, sebagai pengganti sumber energi optik yang umum (seperti lampu kilat, lampu busur, lampu lucutan). Penggunaan laser dioda untuk laser daya rendah akan memberi keuntungan secara teknis dan biaya. Tidak diperlukan sumber daya tegangan tinggi dan sistem pendingin yang rumit.

Penggunaan laser dioda untuk pemompaan adalah dimungkinkan, karena kristal Nd-YAG memiliki spektrum serapan energi yang salah satunya berada di sekitar 790 hingga $820 \mathrm{~nm}$. Panjang gelombang ini adalah pada rentang panjang gelombang yang umum dari laser dioda. Laser dioda yang digunakan pada penelitian ini berkasnya tidak terkolimasi, sehingga penelitian ini juga mencakup sistem pengkolimasian dan pemfokusan berkas laser dioda. Berkas yang sudah terkolimasi dan terfokus ini kemudian diarahkan ke permukaan kristal Nd-YAG, diameter $3 \mathrm{~mm}$ dan panjang $5 \mathrm{~mm}$, yang berada didalam rongga resonator, untuk proses pemompaan.

Luaran berkas laser yang keluar dari resonator diamati dengan alat Optical Spectrum Analyzer (OSA). Dari hasil pengamatan dan pengukuran yang telah dilakukan terhadap berkas

*E-MAIL: muchiar2003@yahoo.com emisi kristal Nd-YAG, tanpa melalui kolimator, dalam rentang panjang gelombang 1040 hingga $1140 \mathrm{~nm}$, muncul 10 buah puncak gelombang emisi, yaitu sekitar 1052, 1061, 1064, 1068, 1073, 1078, 1105, 1112, 1115, dan 1122 nm. Hasil ini bersesuaian dengan tansisi utama dari kristal Nd-YAG pada temperatur ruang.

Dengan pengaturan kedua cermin resonator, maka luaran yang dihasilkan bisa diperoleh hanya pada satu panjang gelombang, yaitu $1064 \mathrm{~nm}$. Dan hal ini membuktikan bahwa laser dioda dapat digunakan sebagai sumber energi optik untuk laser Nd-YAG gelombang kontinyu daya rendah.

\section{DASAR TEORI}

Kristal Nd-YAG (Neodymium-Yttrium Aluminum Garnet) merupakan jenis medium laser zat padat yang sangat populer. YAG $\left(\mathrm{Y}_{3} \mathrm{Al}_{5} \mathrm{O}_{12}\right)$ yang di doping dengan Neodymium $(\mathrm{Nd})$, menghasilkan kristal dengan kekuatan dan kekerasan cukup tinggi, secara optik kristal ini merupakan kristal isotropik dengan struktur kubik, memiliki fluorescent linewidth yang sempit, menghasilkan penguatan yang tinggi, dan ambang yang rendah untuk operasi laser.

Kristal Nd-YAG memiliki beberapa daerah spektrum sera-

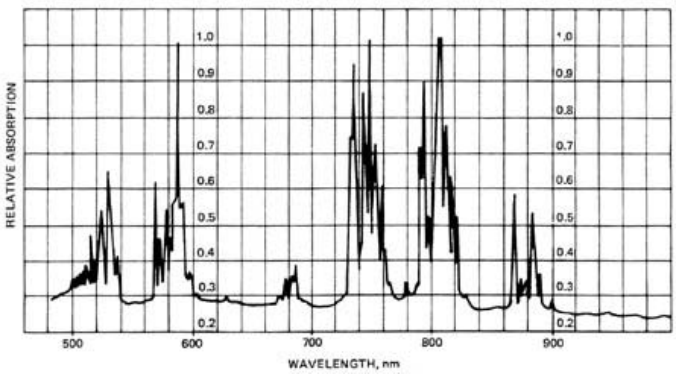

Gambar 1: Spektrum serapan Nd-YAG 


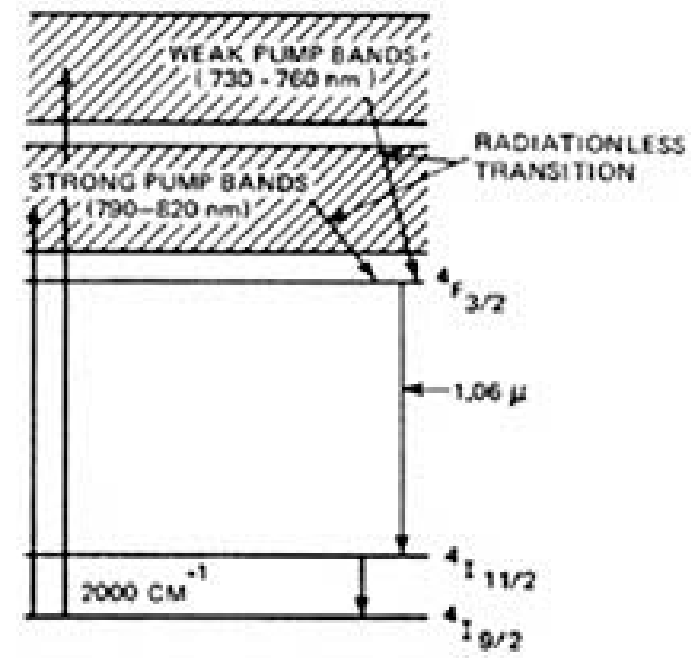

Gambar 2: Diagram sederhana aras-energi dari laser empat-aras.

pan energi (Gambar 1), dua diantaranya adalah pada daerah dari $(730$ - 760) nm dan $(790$ - 820) nm, daerah merah-infra dekat. Laser Nd-YAG merupakan laser sistem empat-aras (Gambar 2), dengan aras dasar ${ }^{4} I_{9 / 12}$. Transisi laser dengan panjang gelombang $1064 \mathrm{~nm}$ berasal dari komponen $\mathrm{R}_{2}$ aras ${ }^{4} F_{3 / 2}$ dan berakhir pada komponen $\mathrm{Y}_{3}$ dari aras ${ }^{4} I_{11 / 2}$.

Salah satu kekurangan dari laser semi-konduktor adalah berkasnya sangat divergen dan penampangnya berbentuk elips. Pengkolimasiannya dapat dilakukan dengan sepasang lensa positif. Dan untuk mendapatkan bintik fokus berpenampang bundar, pemfokusan dapat menggunakan sepasang lensa silindris cembung-datar, dipasang dengan sumbu lensa saling tegak lurus, dan titik fokus keduanya berimpit (Gambar 3).

Lensa $\mathrm{L}_{c}$ berfungsi mensejajarkan berkas asli laser dioda, dan menghasilkan berkas terkolimasi dengan penampang berbentuk elips. Selanjutnya, berkas ini dalam arah vertikal akan difokuskan oleh lensa silindris $\mathrm{L}_{1}$ pada titik $\mathrm{F}$, dan dalam arah horisontal akan difokuskan oleh lensa silindris L2 pada titik yang sama, titik F. Panjang fokus lensa silindris $L_{1}\left(=f_{1}\right)$ dan $\mathrm{L}_{2}\left(=\mathrm{f}_{2}\right)$ ditentukan berdasarkan rasio sudut divergensi dalam arah jari-jari penampang terbesar, $\theta_{1}$, dan arah jari-jari penampang terkecil, $\theta_{2}$,

$$
\frac{\theta_{1}}{\theta_{2}}=\frac{f_{1}}{f_{2}}
$$

Diameter berkas pada titik fokusnya, $D_{f}$, dapat ditentukan

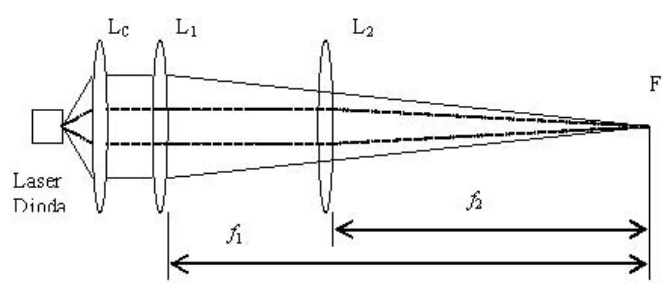

Gambar 3: Sistem pengkolimasian dan pemfokusan berkas laser semikonduktor. dengan persamaan

$$
D_{f}=\left(\frac{4 \lambda}{\pi}\right)\left(\frac{f}{D_{b}}\right)
$$

dengan $\lambda=$ panjang gelombang berkas yang tiba pada lensa, $\mathrm{f}=$ panjang fokus lensa, $D_{b}=$ diameter berkas yang tiba pada lensa. Pada penelitian ini, laser yang dibuat menggunakan resonator plano-konkaf, yang terdiri dari sebuah cermin datar (sebagai cermin belakang) dan sebuah cermin cekung (sebagai cermin depan).

\section{METODOLOGI PENELITIAN}

Secara garis besar model Laser Nd:YAG yang akan dibuat dapat dibagi menjadi dua bagian utama, yaitu sistem pemompaan dan sistem resonator. Semua komponen yang diperlukan adalah yang bisa diperoleh di pasar bebas.

\section{A. Sistem Pemompaan}

Sistem pemompa terdiri dari laser dioda, lensa kolimator untuk menjajarkan berkas laser dioda, dan sepasang sepasang cermin silindris untuk memfokuskan berkas yang terkolimasi menjadi bintik fokus yang bundar (lihat Gambar 3).

Laser dioda yang digunakan sebagai sumber energi optik ditempatkan pada heatsink, sehingga panas yang timbul dapat segera terbuang ke udara bebas. Pendinginan menggunakan heatsink dianggap cukup memadai mengingat daerah kerja laser dioda berkisar antara 25 hingga $50^{\circ} \mathrm{C}$. Laser dioda yang digunakan pada penelitian ini memiliki panjang gelombang rata-rata $804 \mathrm{~nm}$, hanya memerlukan catu daya dengan tegangan 12 Volt dan suplai arus konstan 1,2 A.

Untuk kolimator, pertimbangannya adalah bahwa panjang fokusnya sependek mungkin, untuk mengurangi rugi-rugi optik. Pada penelitian ini digunakan kolimator, dengan NA 0,267 dan panjang fokus $15,0 \mathrm{~mm}$. Untuk mendapatkan berkas yang sejajar atau terkolimasi, titik fokus lensa kolimator harus berimpit dengan sumber cahaya.

Untuk pemfokusan berkas yang sudah terkolimasi, digunakan sepasang lensa silindris cembung-datar yang ditempatkan sedemikian rupa hingga titik fokusnya berimpit. Masing-masing lensa ini hanya memfokuskan berkas dalam arah yang searah dengan permukaan lengkung lensa, sehingga gabungan kedua lensa ini akan menghasilkan bintik fokus yang berbentuk relatif bundar.

\section{B. Sistem Resonator}

Dudukan resonator digunakan logam baja tahan karat, yang mempunyai koefisien muai panjang relatif kecil. Seluruh komponen resonator, yaitu kedua buah cermin, medium laser (kristal Nd-YAG) beserta heatsink ditempatkan pada dudukan ini. Dudukan untuk kristal serta pendinginnya dibuat dari 
logam tembaga, agar mudah menyalurkan panas yang timbul, sedangkan dudukan komponen lainnya dibuat dari paduan logam aluminium.

Resonator yang dipilih untuk sistem laser ini adalah resonator plano-konkaf, yang memiliki sebuah cermin datar (cermin belakang) dan sebuah cermin cekung (cermin depan atau cermin transmisi). Cermin belakang diberi lapisanlapisan yang meloloskan panjang gelombang berkas laser dioda dan memantulkan sempurna $(\approx 100 \%)$ berkas laser $\mathrm{Nd}$ YAG yang dihasilkan, pada panjang gelombang $1064 \mathrm{~nm}$. Cermin depan diberi lapisan yang bersifat memantulkan sebagian besar $(\approx 90 \%$ ) berkas dengan panjang gelombang $1064 \mathrm{~nm}$ dan meloloskan sisanya. Pemilihan cermin seperti ini dimaksudkan agar sebagian besar berkas laser yang dihasilkan oleh kristal berosilasi dan beresonansi, sehingga menghasilkan penguatan energi optik yang besar didalam resonator. Sedangkan sebagian berkas yang lolos adalah merupakan luaran dari laser Nd:YAG. Kedua buah cermin penempatannya sedemikian rupa hingga sumbunya berimpit.

\section{Pengukuran}

Pengamatan dan pengukuran yang dilakukan pada penelitian ini dilakukan dua tahap. Pada pengukuran tahap pertama, akan dilihat apakah transmisi-transmisi utama kristal Nd-YAG akan muncul atau terjadi setelah proses pemompaan berlangsung. Tahapan ini bertujuan memastikan bahwa proses pemompaan berlangsung dengan baik. Pada tahap kedua, diamati dan diukur luaran dari resonator. Tahapan ini bertujuan untuk memastikan bahwa cermin-cermin resonator sudah terpasang dengan baik dan panjang rongga resonator sudah tepat untuk menghasilkan resonansi maksimum.

Dengan data-data pengamatan yang diperoleh dapat dilakukan penyesuaian-penyesuaian yang diperlukan terhadap sistem pemompaan dan kedua cermin resonator hingga didapatkan rongga resonator yang menghasilkan berkas yang diinginkan, yaitu laser dengan panjang gelombang $1064 \mathrm{~nm}$.

Pengamatan dan pengukuran yang dilakukan dengan alat ukur Optical Spectrum Analyzer (OSA). Alat ukur ini digunakan karena dua besaran sekaligus dapat diukur, yaitu intensitas relatif dan spektrum panjang gelombang laser.

\section{HASIL DAN DISKUSI}

\section{A. Hasil perhitungan untuk sistem kolimasi dan pemfokusan}

Pilihan lensa kolimator dengan panjang fokus $15,3 \mathrm{~mm}$ memberikan jarak antara permukaan case kolimator terhadap titik fokusnya sebesar $6,8 \mathrm{~mm}$. Dari pengukuran, diperoleh jari-jari berkas sejajar dalam arah vertikal sebesar $\pm 3,70 \mathrm{~mm}$, dan dalam arah horisontal sebesar $0,68 \mathrm{~mm}$.

Laser dioda yang digunakan pada penelitian ini, mempunyai sudut divergensi berkas terbesar 33 derajat, dan terkecil 5,7 derajat. Dari Pers.1, maka perbandingan panjang fokus lensa silindris yang diperlukan adalah

$$
\begin{aligned}
\frac{\theta_{1}}{\theta_{2}} & =\frac{f_{1}}{f_{2}}=\frac{3,3}{5,7}=5,8 \\
f_{1} & =5,8 f_{2}
\end{aligned}
$$

Panjang fokus lensa yang sesuai dengan perbandingan di atas adalah cukup sulit, sehingga perlu dilakukan penyesuaian. Untuk itu, dipilih lensa silindris pertama, $\mathrm{L}_{1}$, panjang fokusnya, $f_{1}=150 \mathrm{~mm}$, dan lensa silindris kedua, $L_{2}$, panjang fokusnya, $\mathrm{f}_{2}=25 \mathrm{~mm}$. Berdasarkan nilai-nilai di atas, akan diperoleh diameter bintik fokus terbesar sebesar

$$
\begin{aligned}
D_{f 1} & =\left(\frac{4 \lambda}{\pi}\right)\left(\frac{f}{D_{b}}\right) \\
& =\left(\frac{4 x 802 x 10^{-6} \mathrm{~mm}}{\pi}\right)\left(\frac{150 \mathrm{~mm}}{3,7 \mathrm{~mm}}\right) \\
& =41,5 \mu \mathrm{m}
\end{aligned}
$$

dan diameter bintik fokus terkecil sebesar

$$
\begin{aligned}
D_{f 2} & =\left(\frac{4 \lambda}{\pi}\right)\left(\frac{f}{D_{b}}\right) \\
& =\left(\frac{4 x 802 x 10^{-6} \mathrm{~mm}}{\pi}\right)\left(\frac{25 \mathrm{~mm}}{0.85 \mathrm{~mm}}\right) \\
& =44,1 \mu \mathrm{m}
\end{aligned}
$$

Selanjutnya dari hasil perhitungan bintik fokus di atas, maka untuk masing-masing diameter berkas luaran diperoleh kedalaman fokusnya sebesar 82,8 dan $88,2 \mu \mathrm{m}$.

\section{B. Hasil pengamatan dan pengukuran terhadap spektrum laser dioda}

Untuk mengetahui panjang gelombang sesungguhnya dari laser dioda yang digunakan, maka dilakukan pengukuran spektrumnya dengan menggunakan OSA. Hasil yang didapat menunjukkan bahwa lebar spektrum berkisar antara sekitar 799 hingga sekitar $807 \mathrm{~nm}$, pada arus masukan maksimum, 1,2 A, sehingga panjang gelombang rata-rata dari laser dioda yang digunakan adalah sekitar $804 \mathrm{~nm}$.

\section{Hasil pengamatan dan pengukuran terhadap spektrum emisi kristal Nd-YAG}

Pengukuran terhadap berkas emisi kristal Nd-YAG dengan OSA, pada tingkat daya pemompaan maksimum (1,2 A), menunjukkan munculnya 10 buah puncak gelombang emisi, yaitu disekitar 1052, 1061, 1064, 1068, 1073, 1078, 1105, 1112, 1115, dan 1122 nm. (Gambar 5(a))

\section{Hasil pengamatan dan pengukuran terhadap luaran resonator}

Hasil pengukuran terhadap luaran model laser Nd-YAG yang telah dibuat dengan menggunakan OSA menunjukkan 


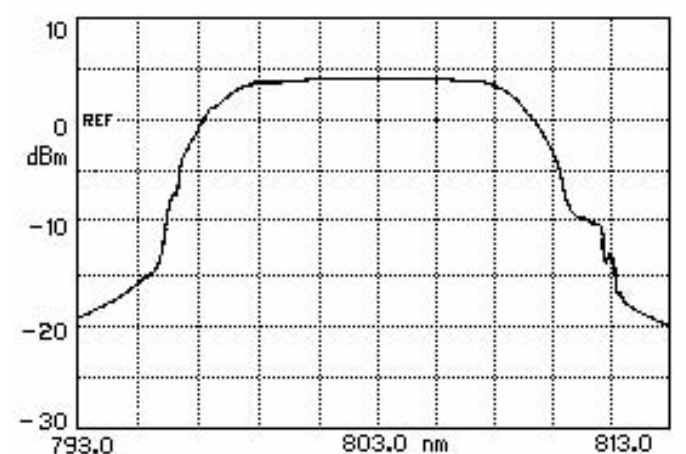

Gambar 4: Spektrum luaran laser dioda tipe LN808N1.
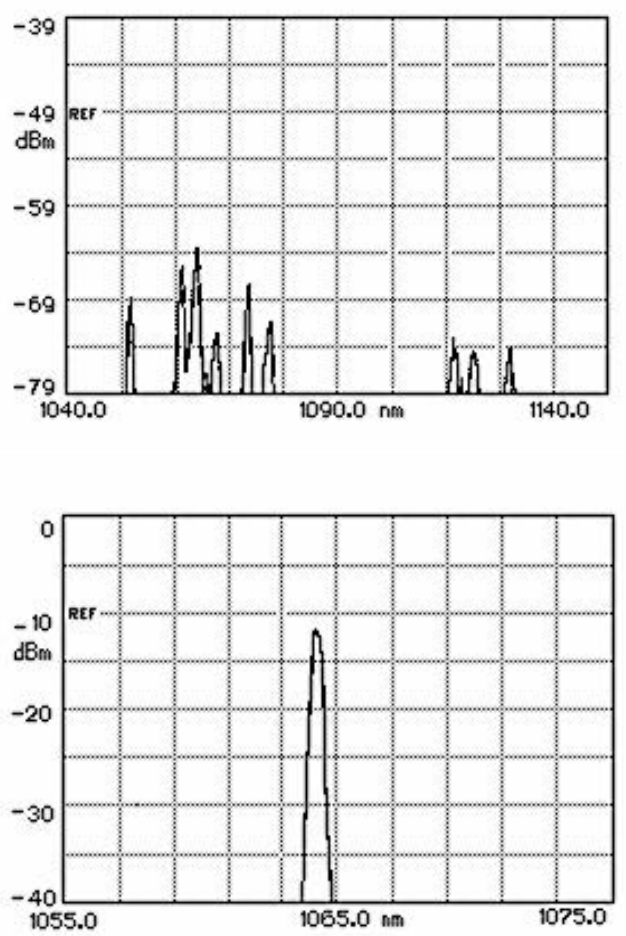

Gambar 5: (a). Spektrum emisi kristal Nd-YAG, (b)spektrum luaran laser model laser Nd-YAG

pada arus pemompaan laser dioda yang maksimum (1,2 A) telah menghasilkan berkas laser Nd-YAG dengan panjang $1064 \mathrm{~nm}$ dengan tingkat intensitas terukur sekitar $\pm(-11)$ dBm. (Gambar 5(b))

\section{E. Diskusi}

1. Berdasarkan hasil perhitungan di atas, terdapat perbedaan sebesar 2,7 $\mu \mathrm{m}$ (sekitar 6,\%) diantara kedua bintik fokus yang dihasilkan lensa silindris. Untuk kepentingan pemompaan perbedaan sekecil ini tidak akan berpengaruh, karena seluruh berkas masih terfokus pada permukaan kristal Nd-YAG yang $3 \mathrm{~mm}$.

2. Dari pengamatan terhadap hasil pengukuran spektrum emisi dengan OSA, terlihat bahwa pada daya laser dioda yang maksimum, akan diemisikan panjangpanjang gelombang yang sesuai dengan teori, seperti ditunjukkan dalam Gambar 5(b). Intensitas tertinggi berada pada panjang gelombang $1064 \mathrm{~nm}$.

3. Hasil pengamatan terhadap berkas luaran resonator yang menunjukkan bahwa laser yang dipancarkan oleh sistem hanya mengandung satu puncak panjang gelombang, yaitu $1064 \mathrm{~nm}$, menunjukkan bahwa resonator dari model laser Nd:YAG yang dirancang telah bekerja dengan baik, sesuai dengan harapan.

4. Untuk panjang gelombang $1064 \mathrm{~nm}$, tingkat intensitas dari berkas laser luaran model laser Nd:YAG yang diteliti adalah sekitar $-11 \mathrm{dBm}$, sedangkan dari data pengamatan untuk emisi kristal Nd:YAG, pada panjang gelombang dan tingkat energi pemompaan yang sama, adalah sekitar $-62 \mathrm{dBm}$. Berdasarkan data ini, untuk panjang gelombang $1064 \mathrm{~nm}$, telah terjadi penguatan oleh resonator sebesar $51 \mathrm{dBm}$ atau berarti penguatan daya sekitar 105 kali, dengan demikian resonator yang digunakan telah menghasilkan penguatan yang besar sekali.

5. Apabila dibandingkan dengan tingkat intensitas dari luaran laser dioda yang terukur sebesar $7 \mathrm{dBm}$, dibandingkan dengan tingkat intensitas model laser yang diteliti $-11 \mathrm{dBm}$, maka terdapat perbedaan sebesar kurang lebih $18 \mathrm{dBm}$. Data ini menunjukkan bahwa efisien energi dari model laser yang diteliti adalah $2 \%$.

\section{SIMPULAN}

Dari penelitian ini dapat disimpulkan bahwa model laser Nd-YAG yang telah dibuat dan diteliti, umumnya, telah bekerja sesuai dengan harapan, menghasilkan laser dengan panjang gelombang $1064 \mathrm{~nm}$. Resonator yang digunakan juga sudah bekerja cukup baik dengan menghasilkan penguatan terhadap emisi kristal Nd-YAG sekitar $10^{5}$ kali. Akan tetapi dilihat dari segi efisiensi energi optik terlihat masih agak rendah, yaitu hanya $2 \%$ dari energi optik laser dioda dengan panjang gelombang $804 \mathrm{~nm}$ yang diubah menjadi energi optik laser Nd-YAG dengan panjang gelombang $1064 \mathrm{~nm}$.

Berdasarkan hasil yang didapat ada beberapa saran yang perlu disampaikan untuk meningkatkan efisiensi, yaitu:

1. Dudukan-dudukan komponen optik lebih disempurnakan lagi, dibuat dengan ketelitian yang lebih tinggi.

2. Dudukan cermin belakang resonator dilengkapi dengan mikrometer yang halus agar pengaturannya dapat lebih teliti. Akan lebih baik lagi bila pengaturan juga dilengkapi dengan piezo-elecric. 
[1] Walter Koechner, Solid-State Laser Engineering, BerlinHeidelberg- New York-London-Paris-Tokyo, Springer-Verlag (1988).

[2] U. Johan, et al., $1 \mathrm{~W} \mathrm{CW}$ diode-pumped $\mathrm{N}$ laser for coherent space communication system. Optical Communication II, SPIE Vol.1552 (1991).

[3] MELLES GRIOT,Fundamental Optics, Bagian dari Katalog Manufacturers of Optics, Opto-Mechanics, Laser and Instrumen- tation.

[4] William M. Steen, Laser Material Processing, London-BerlinHeidelberg-New York-Paris-Tokyo-Hongkong-BarcelonaBudapest, Springer-Verlag, (1994).

[5] Muchiar, Penelitian Pembuatan Sistem Pemompa Laser Nd:YAG Menggunakan Daya Pompa Optik Laser dioda,Laporan Penelitian, Puslitbang Fisika Terapan-LIPI 